\title{
Aporte de la biología molecular en el diagnóstico de infecciones respiratorias agudas
}

\author{
ISOLDA BUDNIK O.*, MARCELA FERRÉS G.*,*****, TRINIDAD PARDO T.*, JAVIERA EDWARDS T.**, \\ GONZALO LABARCA T.**, FELIPE REYES Z.**, CONSTANZA MARTINEZ-VALDEBENITO***, \\ LUISA MONTECINOS P.*** y CECILIA PERRET P.*
}

\section{Contribution of multiplex respiratory molecular panel to the diagnosis of acute respiratory infections}

Objective: To assess the performance of multiplex-PCR for diagnosis of respiratory viruses in parallel with direct fluorescence assay (DFA). We assessed the performance and co-infection diagnosis of molecular respiratory panel PCR (MRP-PCR) and DFA in hospitalized and outpatients. Results: 8535 samples were included, 1792 tested by MRP-PCR (46.9\% positive) and 6743 by DFA (35.1\% positive). MRP-PCR diagnosed co-infection in $21.3 \%$ and DFA in $1.8 \%$ of the samples. Rhinovirus was the most common virus in any age group. In 210 patients both tests were done; 100 were positive by MRP-PCR and 18 by DFA. Positive concordance value was $6.2 \%$. 85 samples were positive only by $M R P-P C R$ and in 42 of them only novel respiratory viruses were identified. Performance of MRP-PCR was statistically significant compared DFA for traditional respiratory viruses. Discussion: Multiplex PCR has shown better sensitivity, may expand the etiologic spectrum of respiratory infections and detect a higher number of co-infections.

Key words: Respiratory Tract Infections; Viruses; Rhinovirus ; Fluorescence; Multiplex Polimerase Chain Reaction.

\section{Resumen}

Objetivo: Evaluar la contribución del panel respiratorio molecular por reacción en cadena de la polimerasa-multiplex (PRM-RPC) en paralelo a la de inmunofluorescencia directa (IFD) al diagnóstico de infecciones respiratorias. Analizamos y comparamos el rendimiento y diagnóstico de co-infección de PRM-RPC con IFD en pacientes hospitalizados y ambulatorios. Resultados: Se analizaron 8535 muestras; 1792 por PRM-RPC (46,9\% positivas) y 6743 por IFD (35,1\% positivas). La co-infección fue $21,3 \%$ por PRM-RCP y 1,8\% por IFD. El virus más frecuente fue rinovirus a toda edad. Se analizaron 210 pacientes por ambos métodos; resultaron positivas 100 por PRM-RPC y 18 por IFD, concordancia positiva de 6,2\%. 85 muestras fueron solo positivas por PRM-RPC, 42 diagnosticaron nuevos virus respiratorios. El rendimiento de PRM-RPC fue significativamente mayor que el de IFD para virus respiratorios tradicionalmente diagnosticados. Conclusiones: La RCP-multiplex tiene mejor sensibilidad, podría expandir el espectro etiológico de infecciones respiratorias y detectar un mayor número de co-infecciones comparado a IFD.

Palabras clave: Infecciones Respiratorias; Virus; Rinovirus; Fluorescencia; Reacción en Cadena de la Polimerasa-Multiplex.

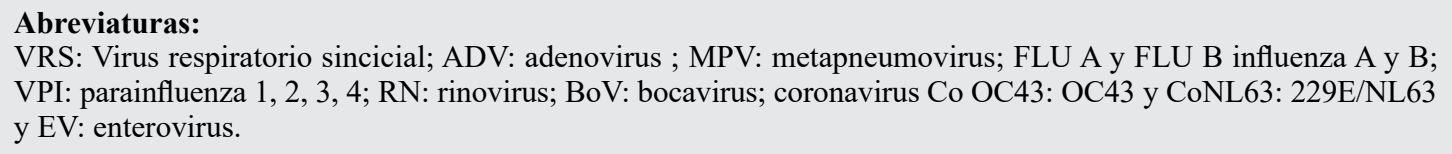

Fuente de financiamiento: ninguna.

* Escuela de Medicina, División de Pediatría, Pontificia Universidad Católica de Chile.

** Escuela de Medicina, Pontificia Universidad Católica de Chile.

*** Laboratorio de Infectología y Virología Molecular. Pontificia Universidad Católica de Chile. 


\section{Introducción}

Las infecciones respiratorias agudas (IRA) son un importante problema de salud pública a nivel mundial, por su morbimortalidad, particularmente en el grupo de pacientes inmunosuprimidos $^{1-3}$. En Chile, se describe como la segunda causa de muerte en niños y la tercera causa de muerte en adultos ${ }^{4,5}$. Además, las IRA son la primera causa de consultas ambulatorias y hospitalizaciones, así como también una importante causa de ausentismo escolar y laboral ${ }^{6}$. Si bien los virus son los agentes que con mayor frecuencia producen IRA a todas las edades, comparativamente son más comunes en niños que en adultos y causan cuadros más graves en grupos de riesgo, como menores de 2 años, ancianos, inmunosuprimidos y pacientes con comorbilidades $^{4,7}$. En estos pacientes es fundamental encontrar técnicas diagnósticas rápidas, sensibles y precisas, especialmente en el estudio de infecciones respiratorias bajas ${ }^{8}$.

Se describe que 20 a $30 \%$ de los pacientes con síntomas respiratorios quedan sin diagnóstico etiológico, utilizando inmunofluorescencia directa (IFD) como método tradicional de detección viral ${ }^{9}$. Durante los últimos años, ha habido un crecimiento exponencial en el desarrollo de técnicas para la identificación de agentes patógenos respiratorios, en base a la amplificación de ácidos nucleicos. Esto ha cambiado nuestra visión de la etiología y espectro clínico de las infecciones respiratorias virales, aumentado la identificación de nuevos agentes detectados (VPI4, RV, BoV, Co OC43, Co NL63 y EV) y mejorando la identificación de los tradicionalmente reconocidos, permitiendo evaluar el rol de estos nuevos virus que hasta ahora no han sido del todo estudiados ${ }^{1,2,7}$. Cada vez hay más estudios que demuestran las ventajas de la reacción polimerasa en cadena (RPC) multiplex, por sobre los métodos de detección tradicionales para virus respiratorios, dejando a estas últimas más obsoletas ${ }^{1,2,6-11}$. Se ha descrito incrementos en el diagnóstico de patógenos respiratorios en 85 a $93 \%$, permitiendo además la búsqueda simultánea de varios virus respiratorios, que podría incidir en la evolución del paciente pediátrico ${ }^{12}$. Algunos autores sugieren que la co-infección viral, aumenta los tiempos de hospitalización y se relaciona con evoluciones más graves ${ }^{12}$. Nuestro objetivo principal fue evaluar el aporte del uso de una nueva RPC multiplex implementada en nuestro hospital, para el diagnóstico de infecciones respiratorias, en población pediátrica y adulta en paralelo con el tradicional panel por IFD.

\section{Método}

Se incluyeron todas las muestras respiratorias de pacientes pediátricos y adultos con IRA enviadas a estudio de virus respiratorios al Laboratorio de Infectología y Virología Molecular de la Pontificia Universidad Católica de Chile entre junio de 2011 y agosto de 2012. Las muestras fueron tomadas por hisopado nasofaríngeo, aspirado traqueal o lavado bronquio-alveolar en pacientes pediátricos y adultos tanto ambulatorios como hospitalizados. A éstas se les realizó IFD, panel respiratorio molecular por RPC (PRM-RPC) o ambas técnicas según lo solicitado por el médico tratante. La IFD se realizó mediante un kit comercial (D3 Ultra 8TM DFA Respiratory Virus Screening and Identification Kit $(\mathrm{B})$ que detecta 8 agentes: VRS, ADV, MPV, FLU A y FLU B y VPI 1, 2, 3. Para el PRM-RPC multiplex se utilizó el kit comercial (Seegene RD15 OneStep ACE Detection Seeplex () que detecta 15 agentes: VRS A y B, ADV, MPV, FLU A y FLU B, VPI 1, 2, 3, 4, RV, BoV, Co OC43, Co NL63 yEV.

Se obtuvo información demográfica de los pacientes, fecha y origen de la muestra y su resultado. Para la comparación de rendimiento y concordancia entre PRM-RPC e IFD se seleccionaron pacientes que contaran con muestras analizadas por ambos métodos tomadas con menos de 5 días de diferencia entre ellas. El estudio de concordancias entre ambas técnicas se realizó en base a los virus incluidos en el panel por IFD. Se analizó el rendimiento también para cada grupo etario y para pacientes hospitalizados y ambulatorios. Para efectos de análisis se definieron 3 grupos etarios: niños menores de 5 años, niños entre 5 y 15 años y adultos mayores de 15 años. Además se analizó el subgrupo menor de 2 años y mayor de 60 años. Para el análisis de concordancia se utilizaron las siguientes definiciones. Concordancia positiva entre las pruebas: muestra positiva por IFD y por PRM-RPC para un mismo virus. Concordancia negativa entre las pruebas: muestra negativa por IFD y por PRM-RPC. Discordancia positiva entre las pruebas: muestra positiva por PRM-RPC y negativa por IFD para un mismo virus. Discordancia negativa entre las pruebas: muestra negativa por PRM-RPC y positiva por IFD para un mismo virus.

Los datos demográficos, clínicos y relacionados con el procedimiento fueron expresados en porcentajes absolutos y promedios \pm desviación estándar (DS). Se utilizaron pruebas no paramétricas: U-Mann Whitney para variables continuas y para variables categóricas la prueba de $\chi^{2}$ o prueba de Fischer según correspondiese. El aná- 
lisis de concordancia entre las distintas técnicas utilizó el test de Kappa. Se consideró un resultado estadísticamente significativo con valor $\mathrm{p}<0,05$ y odds ratio ajustado (OR) con sus respectivos intervalos de confianza al 95\%. Todos los datos fueron analizados usando el software SPSS 16.0 (SPSS Imc, Chicago, Illinois).

Este estudio fue aprobado por el comité de ética de nuestro hospital. Se solicitó la dispensa del consentimiento informado para utilizar los resultados de los exámenes virológicos señalados y los datos fueron obtenidos manteniendo la confidencialidad de los sujetos.

\section{Resultados}

Se analizaron 8.535 muestras, $4.319(50,6 \%)$ correspondieron a pacientes del género masculino y $3.095(36,3 \%)$ a pacientes hospitalizados. El $56,5 \%$ de las muestras correspondieron a pacientes $<5$ años. Se incluyeron 1792 (20,1\%) mues- tras analizadas por PRM-RPC, $6743(79,0 \%)$ muestras analizadas por IFD y 210 pacientes que contaban con muestras estudiadas por ambos métodos. En la Figura 1 vemos la distribución temporal de agentes detectados por PRM-RPC e IFD.

\section{Análisis de PRM-RPC}

El promedio de edad de los pacientes cuyas muestras fueron analizadas por esta técnica fue de 26,6 años (0-108,2 años). Resultaron positivas 841 muestras $(46,9 \%)$, con $481(57,2 \%)$ casos provenientes de pacientes hospitalizados y con un total 179 casos $(21,3 \%)$ de co-infecciones, 157 $(87,7 \%)$ casos con dos virus y 22 casos con tres virus, siendo el VRS la asociación más frecuente. Las etiologías identificadas con mayor frecuencia fueron RV, VRS y VPI en menores de 5 años y RV y FLU A en mayores de 15 años. El rendimiento para los virus tradicionalmente diagnosticados fue de $67,5 \%$ para esta técnica. La Tabla 1 describe los resultados obtenidos por PRM-RPC

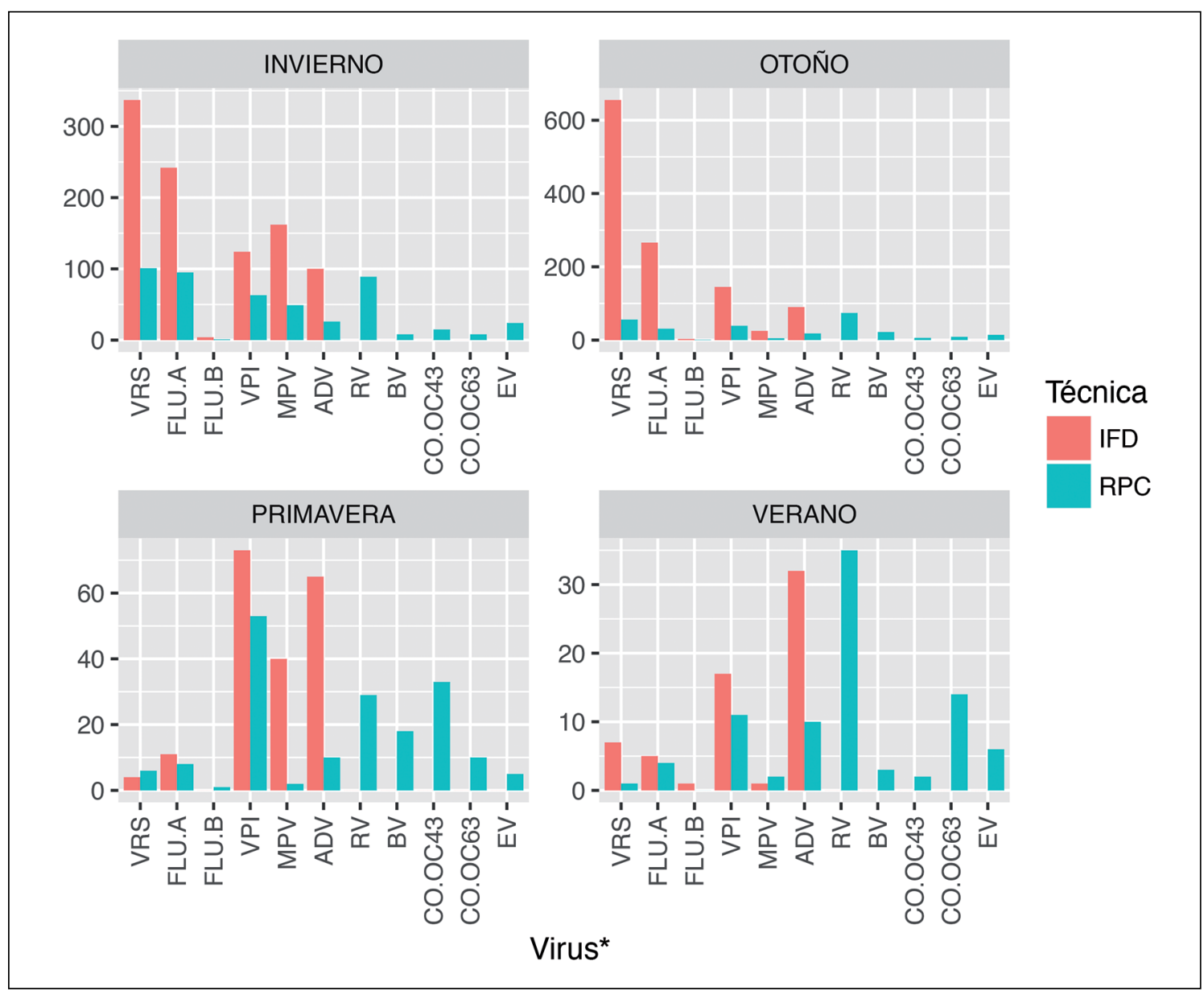

Figura 1. Distribución estacional de agentes virales detectados por Reacción en cadena de la polimerasa multiplex (RPC) e Inmunofluorescencia directa (IFD). La altura de cada columna representa el número de muestras positivas para cada agente viral obtenido con RPC e IFD. Período junio 2011-agosto 2012. *Según abreviaturas al comienzo del texto. 
y separados por grupo etario en cuanto a positividad, co-infección y a etiologías identificadas.

\section{Análisis de IFD}

El promedio de edad de los pacientes cuyas muestras fueron analizadas por esta técnica fue de 17,9 años (0-101,4 años). Resultaron positivas 2368 muestras $(35,1 \%)$, con $410(17,3 \%)$ casos provenientes de pacientes hospitalizados y con un total de 43 casos $(1,8 \%)$ de co-infecciones, todas dobles. Por esta técnica se encontraron signifi- cativamente menos co-infecciones comparado a PRM-RPC $(\mathrm{p}<0,0000001)$ y la asociación más frecuente fue la de VRS con algún otro virus. La etiología identificada con mayor frecuencia por IFD fue VRS en menores de 5 años y FLU A en mayores de 5 años. El rendimiento para los virus tradicionalmente diagnosticados fue de $35,1 \%$ para esta técnica. La Tabla 2 describe los resultados obtenidos por IFD y separados por grupo etario en cuanto a positividad, co-infección y a etiologías identificadas.

Tabla 1. Resultados obtenidos por PRM-RPC según grupo etario en cuanto a positividad, co-infección y a etiologías virales identificadas

\begin{tabular}{|c|c|c|c|c|c|c|c|}
\hline $\begin{array}{l}\text { n muestras (\%) } \\
\mathrm{n}=1.792(100) \\
\text { Mediana (años) }\end{array}$ & \multicolumn{2}{|c|}{$\begin{array}{l}\mathbf{n}<5 \text { años }(\%) \\
n=829(46,3) \\
1,2\end{array}$} & & $\begin{array}{l}\text { n 5-15 años (\%) } \\
\mathrm{n}=163(9,1) \\
9,1\end{array}$ & \multicolumn{2}{|c|}{$\begin{array}{l}\mathbf{n}>\mathbf{1 5} \text { años }(\%) \\
\mathrm{n}=800(44,6) \\
58,3\end{array}$} & \multirow[b]{2}{*}{$\geq 60 \mathrm{a}$} \\
\hline $\begin{array}{l}\text { n muestras positivas }(\%) \\
\mathrm{n}=841(46,9)\end{array}$ & $\begin{array}{c}\text { Total } \\
508(61,3)\end{array}$ & $\begin{array}{l}<2 \text { a } \\
337\end{array}$ & $\begin{array}{c}\geq 2 \mathbf{a} \\
171\end{array}$ & $\begin{array}{c}\text { Total } \\
78(47,9)\end{array}$ & $\begin{array}{c}\text { Total } \\
255(31,9)\end{array}$ & $<60$ a & \\
\hline \multicolumn{8}{|l|}{ Virus identificado (\%) } \\
\hline RV & $134(16,2)$ & 96 & 38 & $26(16,0)$ & $67 \quad(8,4)$ & 33 & 34 \\
\hline VRS & $124(15,0)$ & 87 & 37 & $6 \quad(3,7)$ & $34 \quad(4,2)$ & 17 & 17 \\
\hline VPI & $110(13,3)$ & 59 & 51 & $8 \quad(4,9)$ & $48 \quad(6,0)$ & 22 & 26 \\
\hline $\mathrm{ADV}$ & $58 \quad(7,0)$ & 37 & 21 & $6 \quad(3,7)$ & $9 \quad(1,1)$ & 5 & 4 \\
\hline $\mathrm{BoV}$ & $46 \quad(5,5)$ & 34 & 12 & $4 \quad(2,4)$ & $1 \quad(0,1)$ & 0 & 1 \\
\hline MPV & $45 \quad(5,4)$ & 32 & 13 & $4 \quad(2,4)$ & $25 \quad(3,1)$ & 15 & 10 \\
\hline FLU A & $44 \quad(5,3)$ & 26 & 18 & $25(15,3)$ & $69 \quad(8,6)$ & 45 & 24 \\
\hline $\mathrm{CO} \mathrm{OC43}$ & $37 \quad(4,5)$ & 25 & 12 & $6 \quad(3,7)$ & $13 \quad(1,6)$ & 5 & 8 \\
\hline $\mathrm{EV}$ & $29 \quad(3,5)$ & 22 & 7 & $4 \quad(2,4)$ & $16 \quad(2,0)$ & 10 & 6 \\
\hline CO NLS63 & $28 \quad(3,4)$ & 18 & 10 & $3 \quad(1,8)$ & $10 \quad(1,3)$ & 5 & 5 \\
\hline FLU B & $2 \quad(0,2)$ & 2 & 0 & $1 \quad(0,6)$ & $0 \quad(0,0)$ & 0 & 0 \\
\hline $\begin{array}{l}\text { Co-infección (\%) } \\
\mathrm{n}=179(21,3)\end{array}$ & $130(25,6)$ & & & $15(19,2)$ & $34(13,3)$ & & \\
\hline
\end{tabular}

El significado de las abreviaturas de los virus identificados está indicado al comienzo del texto. PRM-RPC: Reacción en cadena de la polimerasa multiplex. a: años.

Tabla 2. Resultados obtenidos por inmunofluorescencia directa (IFD) según grupo etario en cuanto a positividad, co-infección y a etiologías virales identificadas

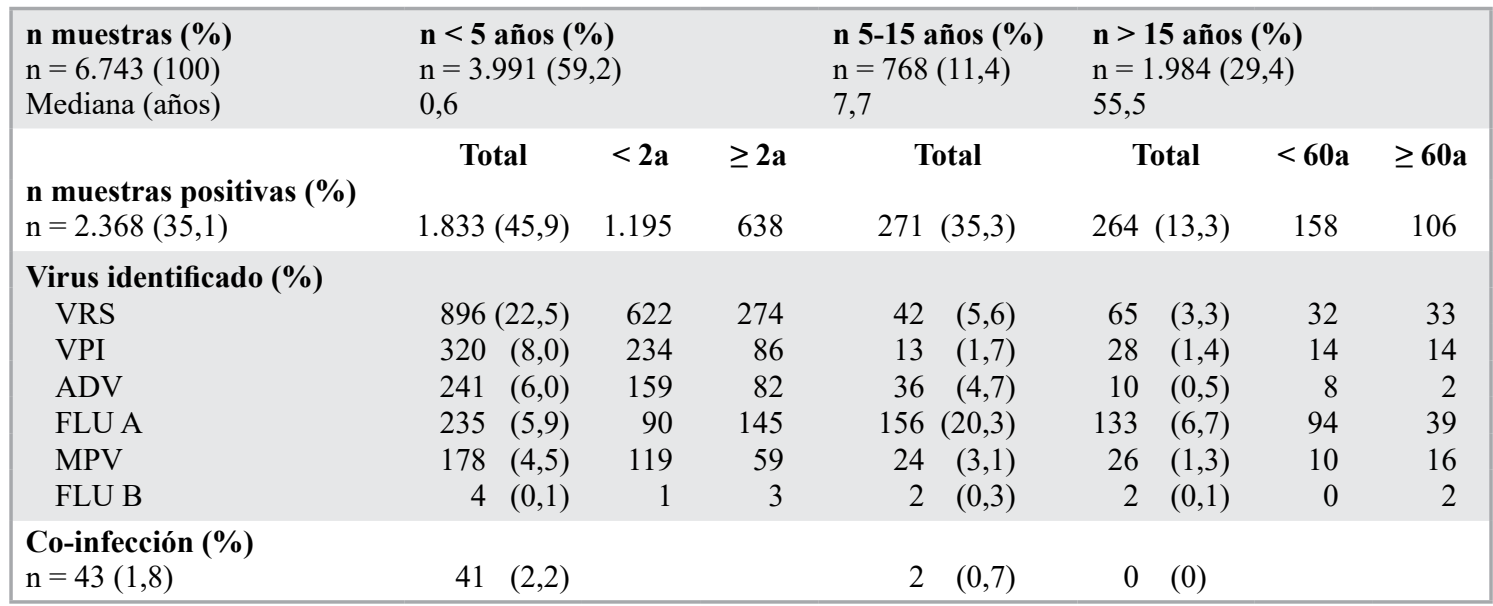

El significado de las abreviaturas de los virus identificados está indicado al comienzo del texto. a: años. 
Tabla 3. Detección de agentes virales en pacientes hospitalizados versus ambulatorios por ambas técnicas inmunofluorescencia directa y Reacción en cadena de la polimerasa multiplex (PRM-RPC)

\begin{tabular}{|c|c|c|c|c|}
\hline \multirow{2}{*}{$\begin{array}{l}\text { Técnica diagnóstica } \\
\text { n muestras }(\%) \\
n=210(100)\end{array}$} & \multicolumn{2}{|c|}{ IFD: Inmunofluorescencia directa } & \multicolumn{2}{|c|}{ PRM-RPC } \\
\hline & $\begin{array}{l}\text { Hospitalizados (\%) } \\
\mathrm{n}=130(61,9)\end{array}$ & $\begin{array}{c}\text { Ambulatorios }(\%) \\
\mathrm{n}=80(38,1)\end{array}$ & $\begin{array}{c}\text { Hospitalizados (\%) } \\
\mathrm{n}=154(73,3)\end{array}$ & $\begin{array}{c}\text { Ambulatorios (\%) } \\
\mathrm{n}=56(26,7)\end{array}$ \\
\hline $\begin{array}{l}\mathbf{n} \text { muestras positivas }(\%) \\
\mathrm{n}=103(49,5)\end{array}$ & $14(10,8)$ & $4(5,0)$ & $71(46,1)$ & $29(51,8)$ \\
\hline Virus identificado (\%) & & & & \\
\hline VRS & $7 \quad(5,4)$ & $1(1,3)$ & $11 \quad(7,1)$ & $4 \quad(7,1)$ \\
\hline VPI & $2(1,5)$ & $1(1,3)$ & $9 \quad(5,8)$ & $9(16,1)$ \\
\hline ADV & $0 \quad(0,0)$ & $0(0,0)$ & $4 \quad(2,6)$ & $3 \quad(5,4)$ \\
\hline FLU A & $3 \quad(2,3)$ & $2(2,5)$ & $11 \quad(7,1)$ & $2(3,6)$ \\
\hline FLU B & $0 \quad(0,0)$ & $0(0,0)$ & $1 \quad(0,6)$ & $0 \quad(0,0)$ \\
\hline MPV & $2 \quad(1,5)$ & $0(0,0)$ & $9 \quad(5,8)$ & $4 \quad(7,1)$ \\
\hline RV & $0 \quad(0,0)$ & $0(0,0)$ & $22(14,3)$ & $9(16,1)$ \\
\hline $\mathrm{BoV}$ & $0 \quad(0,0)$ & $0(0,0)$ & $5 \quad(3,2)$ & $3 \quad(5,4)$ \\
\hline $\mathrm{CO} \mathrm{OC} 43$ & $0 \quad(0,0)$ & $0(0,0)$ & $6 \quad(4,0)$ & $5 \quad(8,9)$ \\
\hline CO NLS63 & $0 \quad(0,0)$ & $0(0,0)$ & $3 \quad(1,9)$ & $1(1,8)$ \\
\hline EV & $0 \quad(0,0)$ & $0(0,0)$ & $0 \quad(0,0)$ & $1(1,8)$ \\
\hline
\end{tabular}

El significado de las abreviaturas de los virus identificados está indicado al comienzo del texto.

\section{Comparación entre PRM-RPC e IFD}

Se analizaron 210 pacientes por ambos métodos. El promedio de edad fue de 23,1 años (0-97 años) y la distribución etaria de los pacientes fue $108(51,4 \%)$ menores de 5 años, $19(9,0 \%)$ entre los 5 y los 15 años y $83(39,5 \%)$ mayores de 15 años. De estos pacientes, $103(49,0 \%)$ resultaron positivos por al menos uno de los métodos diagnósticos. Hubo $100(47,6 \%)$ muestras positivas por PRM-RPC y $18(8,6 \%)$ positivas por IFD $(\mathrm{p}<0,01)$. De los 103 pacientes positivos, 85 (82,5\%) fueron sólo por PRM-RPC, 3 (2,8\%) pacientes sólo por IFD y $15(14,6 \%)$ por ambos métodos. De los 85 positivos sólo por PRM-RPC se identificaron virus no incluidos en el panel de IFD en 42 casos.

Estudio de concordancia: 13 pacientes fueron positivos y 144 fueron negativos para los virus tradicionales por ambas técnicas dando una concordancia positiva de $6,2 \%$ y una concordancia negativa de $68,6 \%$ respectivamente. Cuarenta y ocho pacientes fueron diagnosticados sólo por PRM-RPC dando una discordancia positiva de $22,8 \%$ y 4 pacientes sólo fueron diagnosticados por IFD dando una discordancia negativa de 2,4\%. El test de kappa fue 0,22. RV fue el virus diagnosticado con mayor frecuencia (n $=31$ ) en las muestras positivas por PRM-RPC mientras que VRS $(n=8)$ fue el más frecuente de las muestras positivas por IFD. La detección de agentes en pacientes hospitalizados versus ambulatorios por ambas técnicas se aprecia en la
Tabla 3. De las muestras positivas, el $71,0 \%$ y el $77,8 \%$ (para PRM-RPC e IFD) fueron detectadas en pacientes hospitalizados. Se detectó co-infección en 20 pacientes $(19,4 \%)$ (18 casos con dos virus y 2 casos con tres), todos por PRM-RPC.

\section{Comentarios}

Nuestro estudio muestra que el rendimiento global y por grupo etario fue significativamente mayor por PRM-RPC comparado a IFD. Es importante mencionar que hubo diferencias significativas en las características demográficas y en la proporción de pacientes hospitalizados entre los dos grupos, siendo el grupo de pacientes analizados por IFD en promedio de menor edad y con un porcentaje significativamente menor de pacientes. Estos factores podrían haber influido en el rendimiento de las técnicas. Sin embargo, el grupo de IFD, a pesar de tener una mayor proporción de niños menores de 5 años (que sabemos es el grupo etario que siempre tiene mejor rendimiento en cualquiera de las técnicas de diagnóstico de virus respiratorios), obtuvo un rendimiento menor que PRM-RPC. Por otro lado el hecho de tener mayor proporción de pacientes hospitalizados en el grupo PRM-RPC podría haber sesgado el resultado a favor de esta técnica, situación que se descarta al comparar solo el grupo de hospitalizados donde se mantuvo el mejor rendimiento de PMR-RPC comparado a IFD. 
Cada vez son más los estudios en la literatura biomédica que describen la utilidad de los métodos moleculares por sobre los métodos de detección tradicional de virus respiratorios en términos de su sensibilidad y especificidad ${ }^{1,2,7-11}$. Para los métodos moleculares se ha descrito sensibilidad y especificidad de 88 y $98 \%$ comparado con el 68 y $70 \%$ para la IFD respectivamente ${ }^{9-11}$.

El uso PRM-RCP nos permitió identificar al menos un agente en casi 5 veces más de lo que se hubiese obtenido al utilizar sólo IFD. La literatura describe sensibilidades obtenidas por métodos moleculares para cada uno de los virus pesquisados por IFD, entre $96,6-100 \%$ para VRS, 96,4-100\% para FLU A, 83-91,5\% para FLU B, $84,2-100 \%$ para VPI, 96-100\% para MPV y $78-100 \%$ para $A D V^{10,11}$. No existen reportes en la literatura de concordancias entre IFD y PRMRPC. Sin embargo, nuestra experiencia demostró una alta discordancia positiva, es decir, la técnica de PRM-RCP tiene mucho más capacidad de arrojar un diagnóstico positivo que la IFD y eso sin considerar la ventaja de diagnosticar un espectro más amplio de virus respiratorios. En el análisis específico para cada virus tradicional, la concordancia positiva entre ambos exámenes resultó moderada para VRS y Flu A, siendo insignificante para VPI, MPV y para ADV, lo que apoyaría la mayor utilidad de la PRM-RPC para estos agentes, en especial del ADV. No obstante puede haber infecciones asintomáticas prolongadas por ADV que hacen difícil la interpretación de un examen positivo ${ }^{1}$.

Si comparamos la positividad de los dos métodos por grupo etario observamos que en ambos el mejor rendimiento se observa en los menores de 5 años siendo entre dos y cuatro veces mejor que en los adultos. Estudios previos también han descrito mejor rendimiento con PRM-RPC aumentando significativamente la sensibilidad en la detección de los virus tradicionalmente diagnosticados, así como también para nuevos virus respiratorios, con incrementos desde $30 \%$ a $66,9 \% \%^{9-11,13}$. Si bien hay un notable incremento en la detección de VRS, FLU B y ADV respecto a la IFD, la mayor proporción de incremento en la sensibilidad está dado por agentes no detectados por métodos tradicionales 7 . Gharabaghi y cols., compararon el rendimiento de 4 ensayos comerciales de PRM-RPC con IFD y aislamiento viral en 750 hisopados nasofaríngeos de pacientes pediátricos, obteniendo un porcentaje de positividad adicional de $28,5 \%$, lo que se traduce en un incremento de la sensibilidad de detección de virus respiratorios en niños de un 74,3\% sobre la IFD y del cultivo viral ${ }^{13}$. Kanashiro y cols., estudiaron muestras respiratorias de 39 pacientes con patología cardiaca congénita con síntomas respiratorios por PRM-RPC e IFD, encontrando significativamente mayor porcentaje de positividad en el primer grupo, $51,3 \%$ y $33,3 \%$ respectivamente $^{2}$.

El rendimiento diagnóstico en los adultos fue mucho menor por ambas técnicas comparado con los niños pero esta diferencia se hace muy marcada para IFD que sólo fue capaz de diagnosticar un porcentaje cercano al $15 \%$ de los pacientes adultos con síntomas respiratorios mientras que el diagnóstico se alcanzó casi en un tercio de los pacientes por biología molecular. Estudios en adultos reportan mayor detección para algunos virus respiratorios (VRS, VPI 3 y 4, RV y EV) utilizando métodos de detección molecular, con incrementos en el diagnóstico etiológico de 23,8 a $72,8 \%{ }^{6}$, lo que concuerda con nuestra experiencia, donde la PRM-RPC diagnosticó 4 veces más que la IFD. La menor positividad en los adultos podría estar dada principalmente por el menor tiempo de excreción de virus respiratorios en esta población, menores cargas virales y consulta más tardía. Tomando en cuenta todas estas consideraciones PRM-RPC representa un mejor método de diagnóstico etiológico de infecciones respiratorias agudas en el paciente adulto.

Por otra parte, la tecnología de detección molecular ha llevado al diagnóstico de virus previamente no identificados como son el RV, EV, BoV, VPI4, CoV OC43 y CoV 229E/NL63, algunos de los cuales pudieran asociarse a cuadros de mayor gravedad tanto en infección como agente único como en co-infecciones ${ }^{10,14}$. En nuestro estudio pudimos diagnosticar nuevos virus respiratorios en dos tercios de los pacientes con resultados positivos por PRM-RPC. Particularmente para $\mathrm{RV}$, uno de los más prevalentes a todas las edades y que no puede identificarse por los métodos tradicionales, el PRM-RPC tiene la sensibilidad y especificidad de $100 \%$ y $98 \%$, respectivamente (13). En nuestro estudio la PRM-RPC diagnosticó, tanto en niños como en adultos al RV como el agente más frecuente, lo que no podría haber sido diagnosticado por IFD. Si bien el significado de la detección de RV en infecciones respiratorias bajas sigue siendo controvertido, con las mayor disponibilidad de nuevas técnicas de diagnóstico de virus respiratorios, se describe en forma creciente al RV como el virus más prevalente en la población de menores de 5 años, con frecuencias de hasta $46 \%$, y como la principal causa de hospitalización en menores de 2 años con sibilancias ${ }^{14}$. También se ha asociado de manera importante con el desarrollo y exacerbaciones del asma, tanto en niños como en adultos ${ }^{14,15}$. En niños con 
leucemia también se ha descrito al RV como el agente más frecuentemente identificado en este grupo de pacientes $(22 \%)^{16}$. En niños menores de 5 años le siguió en frecuencia el VRS, que aparece en primer lugar en las muestras estudiadas por IFD. En mayores de 5 años RV comparte el primer lugar junto con FLU A, agente etiológico más frecuentemente pesquisado por IFD en este grupo etario.

Existen muy pocos casos en los que se obtiene el diagnóstico etiológico por IFD y no por PRM-RPC. Se ha descrito que $1,7 \%$ de casos estudiados la IFD salió positiva con PRM-RPC negativa ${ }^{2}$, al igual que en nuestra experiencia en el $1,4 \%$ de los pacientes el diagnóstico fue logrado por IFD solamente.

El aporte clínico de los ensayos con PRMRPC es importante, en cuanto a la información etiológica que nos entregan, permitiéndonos hacer un adecuado diagnóstico para un óptimo tratamiento y manejo del paciente. Esto toma mayor relevancia en aquellos agentes que tienen tratamiento disponible, como el virus influenza, VRS y el ADV cuyo diagnóstico precoz e inicio de terapia determinan la evolución y pronóstico del paciente, específicamente en aquellos susceptibles $^{6,11}$. Además, métodos que nos permitan una mejor detección de virus respiratorios, son fundamentales para realizar intervenciones que influirán en la morbimortalidad de grupos vulnerables, como es determinar el momento de profilaxis en estos pacientes ${ }^{7}$. Esto adquiere trascendencia al ver reportes de prevalencia de virus respiratorios en pacientes pediátricos con patología oncológica, en los que el VRS y FLU A ocupan el segundo y cuarto lugar, respectivamente $^{16}$. En el caso del virus de la influenza, por ejemplo, es fundamental la pronta identificación etiológica y subtipificación, ya que su subtipo es predictor de la actividad de los antivirales disponibles en el mercado ${ }^{13}$. La sensibilidad de estos métodos para la detección de FLU A se describe de hasta un $98,6 \%$, con un incremento de $25,4 \%$ de manera consistente con respecto a los métodos tradicionales ${ }^{1}$. Nuestros resultados mostraron que el porcentaje de positividad para virus FLU A y para VRS por PRM-RPC fue 2,6 y 1,8 veces mayor que por IFD respectivamente. Cabe destacar que aunque la técnica de biología molecular en virus como el VRS tiene mayor rendimiento en todo el espectro etario en los menores de 5 años la IFD sigue siendo una técnica adecuada.

Además de la mayor sensibilidad para la detección etiológica de virus respiratorios tradicionales y del mayor número de agentes virales identificados, los ensayos PRM-RPC han mejorado la identificación de casos con co-infecciones, que pudieran tener importancia clínica, especialmente en el grupo de inmunocomprometidos, pediátricos y con evolución más grave ${ }^{1,2}$.

Algunos estudios reportan detección de infecciones por múltiples virus entre 10 y $37 \%$ de los casos, siendo éstas más altas en niños y en inmunosuprimidos ${ }^{6,12}$. En nuestro estudio se diagnosticó co-infección en un quinto de las muestras positivas por PRM-RPC y en menos de $2 \%$ de las muestras positivas por IFD, siendo el grupo etario con mayor porcentaje de co-infección los menores de 5 años en ambos grupos de estudio. En el grupo de pacientes cuyas muestras fueron procesadas por ambas técnicas, la tasa de detección de co-infección fue menor y sólo se diagnosticó por PRM-RPC. Entre los pacientes que presentaron co-infecciones por dos virus la asociación más común fue la de VRS con algún otro virus, lo que se describe también en la literatura. Mahony et al describen infecciones dobles en 5-8\% de los pacientes, siendo las asociaciones más típicas la de VRS con FLU A, con VPI 3 y con MPV ${ }^{10}$. Infección por dos o más virus se ha diagnosticado entre 12,5 a $16,5 \%$ de los pacientes, siendo el $\mathrm{BoV}$ el agente más frecuentemente encontrado como co-patógeno ${ }^{7}$. Algunos estudios describen co-detección del $\mathrm{BoV}$ con otros agentes entre 60 y $80 \%$ de las muestras, mientras que otros, apoyan el papel del BoV como causante de infecciones respiratorias sólo o como co-patógeno, especialmente en niños pequeños ${ }^{7}$. En nuestra experiencia $\mathrm{BoV}$, fue agente único en el $43,1 \%$ de los casos y co-infección en el 56,9\%. Si bien aún no se conoce del todo la importancia clínica de las infecciones respiratorias por múltiples agentes virales, se presume que pudieran causar cuadros más larvados y graves ${ }^{9}$, especialmente en grupos de riesgo, razón por la que deberían ser mejor estudiadas ${ }^{7,13}$. En nuestro estudio, la presencia de co-infección no se asoció a mayor caso de hospitalizaciones.

Es importante considerar que la presencia de múltiples virus puede ser producto de infecciones previas recientes, que son detectadas por la técnica molecular utilizada y que no necesariamente son responsables de la infección viral activa ${ }^{12}$. Para diferenciarlos, eventualmente se podrían utilizar técnicas moleculares cuantitativas que nos indiquen su estado de actividad, mediante la medición de la carga viral ${ }^{12}$.

Además de lo ya mencionado, otras ventajas de las técnicas de biología molecular son su rapidez, costo/beneficio y el hecho de que el resultado no es fácilmente alterado por la calidad de la muestra y momento de recolección de ésta 
en relación al inicio de los síntomas ${ }^{2,7}$. La velocidad de implementación de técnicas de biología molecular en laboratorios de virología no ha sido muy rápida, considerando los costos directos $\mathrm{e}$ indirectos que se requieren ${ }^{13}$. Hasta ahora, la IFD e indirecta han sido la técnica de detección más utilizada, por ser barata, rápida y fácil de implementar. Sin embargo, los costos de las técnicas de biología molecular han tenido una reducción consistente, dada la capacidad de análisis simultáneo de múltiples virus, lo que reduce volúmenes de reactivos utilizados y aumentan el grado de automatización de la técnica. En la revisión de datos de 661 pacientes pediátricos para la comparación de IFD, cultivo viral y RCP multiplex, se incluyeron tiempo de hospitalización, días de aislamiento, uso de antibióticos y procedimientos médicos. Los resultados mostraron que la RCP multiplex por si sola era la estrategia más costo-efectiva a utilizar cuando la prevalencia de infección era mayor o igual a $11 \%$ y la IFD era la recomendable cuando la prevalencia era menor a $11 \%$, con ahorros de $\$ 290$ dólares por caso y de $\$ 526000$ dólares por año en costos directos ${ }^{11}$. Si bien los métodos de biología molecular son más caros, el implementar una técnica de éstas con detección de múltiples virus, los costos netos se reducirían al bajar costos indirectos que incluyen tiempo de personal entrenado y ahorros al sistema de salud al evitar hospitalizaciones y exámenes innecesarios, dado su superior sensibilidad y especificidad comparado con otras técnicas. Además, al ser métodos menos laboriosos, seguros $\mathrm{y}$ al requerir menos medidas de bioseguridad, permitiría que más laboratorios de virología implementaran esta técnica diagnóstica ${ }^{13}$. Estudios recientes sugieren que el uso de técnicas moleculares para la detección simultánea de 15 virus respiratorios, reducirían en forma significativa el uso de antibióticos; sin embargo, otros estudios plantean que reducciones en los costos serían difíciles de lograr ${ }^{17}$.

Por último, la aparición de estos paneles virales moleculares comerciales abrirá paso a una nueva era en la microbiología de la salud pública, mejorando las notificaciones de virus respiratorios y mejorando la capacidad de detección de patógenos potencialmente pandémicos, así como también emergentes ${ }^{17}$. Creemos que este estudio es un aporte en el área clínica y de laboratorio dado el gran número de muestras que involucra y que nos permitió tener resultados confiables y representativos de la realidad. Con el uso de PRM-RPC pudimos diagnosticar nuevos agentes virales (VPI4, RV, BoV, CoV OC43, CoV NLS63 y EV), que cada vez se describen con mayor frecuencia y que no habrían sido diagnosticados por los métodos tradicionales, identificar subtipos de VRS, detectar mayor porcentaje de co-infecciones, incrementar el rendimiento de los virus tradicionalmente buscados por IFD y calcular las concordancias y discordancias negativas y positivas para estos mismos. Estimamos que constituye la base para realizar nuevos estudios prospectivos para mejorar el entendimiento de las infecciones respiratorias virales en relación a su temporalidad, manifestaciones clínicas y factores de riesgo.

Dentro de las limitaciones de nuestro estudio, cabe mencionar que éste fue retrospectivo, ambas técnicas fueron realizadas solo en 210 pacientes y no de la misma muestra ni necesariamente el mismo día. Esto pudo contribuir a aumentar el porcentaje de negativos y bajar el rendimiento según la temporalidad y el momento en el que se tomaron las muestras. Por otra parte, la naturaleza de este estudio no permitió el cálculo de sensibilidad ni especificidad de las pruebas diagnósticas por lo que no es posible obtener conclusiones definitivas y más certeras en este sentido. Por último, al no tener cuantificación de la carga viral, no podemos atribuir con certeza el papel del agente detectado como etiológico o simplemente detección del genoma viral.

\section{Agradecimientos}

Al Sr. Álvaro Carrasco, quien colaboró en el análisis estadístico.

\section{Bibliografía}

1.- GHARABAGHI F, TELLIER R, CHEUNG R, COLLINS C, BROUKHANSKI G, DREWS S J, et al. Comparison of a commercial qualitative real-time RT-PCR kit Collins C, Broukhanski with direct immunofluorescence assay (DFA) and cell culture for detection of influenza A and B in children. J Clin Virol 2008; 42: 190-3.

2.- KANASHIRO T M, VILAS BOAS L S, THOMAZ A M, TOZETTO-MENDOZA T R, SETSUKO M, MACHADO C M. Identification of respiratory virus in infants with congenital heart disease by comparison of different methods. Rev Inst Med Trop Sao Paulo 2011; 53: 241-6.

3.- BIBBY D F, MCELARNEY I, BREUER J, CLARK D A. Comparative evaluation of the SeegeneSeeplexRV15 and real-time PCR for respiratory virus detection. J Med Virol 2011; 83: 1469-75.

4.- AVENDAÑO L. Infecciones virales respiratorias. Ca- 
pítulo 12. En: de Aguirre Cox., Virología Clínica 1era edición. Santiago, Chile. Mediterráneo. 2011; págs. 117-36.

5.- VALDIVIA G. Epidemiología de la neumonía del adulto adquirida en la comunidad. Rev Chil Enferm Respir 2005; 21: 73-80.

6.- NOLTE F S, MARSHALL D J, RASBERRY C, SCHIEVELBEIN S, BANKS G G, STORCH G A, et al. MultiCode-PLx system for multiplexed detection of seventeen respiratory viruses. J Clin Microbiol 2007; 45: 2779-86.

7.- BONZEL L, TENENBAUM T, SCHROTEN H, SCHILDGEN O, SCHWEITZER-KRANTZ S, ADAMS O. Frequent detection of viral coinfection in children hospitalized with acute respiratory tract infection using a real-time polymerase chain reaction. Ped Infect Dis J 2008; 27: 589-94.

8.- BRIESE T, PALACIOS G, KOKORIS M, JABADO O, LIU Z, RENWICK N, et al. Diagnostic system for rapid and sensitive differential detection of pathogens. Emerg Infect Dis 2005; 11: 310-3.

9.- BELLAU-PUJOL S, VABRET A, LEGRAND L, DINA J, GOUARIN S, PETITJEAN-LECHERBONNIER J, et al. Development of three multiplex RT-PCR assays for the detection of 12 respiratory RNA viruses. J Virol Methods 2005; 126: 53-63.

10.- MAHONY J, CHONG S, MERANTE F, YAGHOUBIAN S, SINHA T, LISLE C, et al. Development of a respiratory virus panel test for detection of twenty human respiratory viruses by use of multiplex PCR and a fluid microbead-based assay. J Clin Microbiol 2007;
45: 2965-70.

11.- MAHONY J B, BLACKHOUSE G, BABWAH J, SMIEJA M, BURACOND S, CHONG S, et al. Cost analysis of multiplex PCR testing for diagnosing respiratory virus infections. J Clin Microbiol 2009; 47: 2812-7.

12.- MARTÍNEZ P, CORDERO J, VALVERDE C, UNANUE N, DALMAZZO R, PIEMONTE P, et al. Coinfección viral respiratoria en niños hospitalizados por infección respiratoria aguda y su impacto en la gravedad clínica. Rev Chil Infect 2012; 29: 169-74.

13.- GHARABAGHI F, HAWAN A, DREWS S J, RICHARDSON S E. Evaluation of multiple commercial molecular and conventional diagnostic assays for the detection of respiratory viruses in children. Clin Microbiol Infect 2011; 17: 1900-6.

14.- BUSSE WW, LEMANSKE R F Jr, GERN J E. Role of viral respiratory infections in asthma and asthma exacerbations. Lancet 2010; 376 (9743): 826-34.

15.- MOHAN A, CHANDRA S, AGARWAL D, GULERIA R, BROOR S, GAUR B, et al. Prevalence of viral infection detected by PCR and RT-PCR in patients with acute exacerbation of COPD: a systematic review. Respirology 2010; 15: 536-42.

16.- KOSKENVUO M, MOTTONEN M, RAHIALA J, SAARINEN-PIHKALA U M, RIIKONEN P, WARIS $\mathrm{M}$, et al. Respiratory viral infections in children with leukemia. Ped Infect Dis J 2008; 27: 974-80.

17.- BRICE G T, DREWS S J, LOW D E. Respiratory virus panels for global surveillance of emerging infectious diseases. J Clin Virol 2007; 40 Suppl 1: S58-60.
Correspondencia a:

Dra. Isolda Budnik Ojeda

Marcoleta 391, 4to piso, Santiago, Chile.

Email: isolbudnik@gmail.com 